\title{
O instrumento como um outro
}

RESUMO: Esse texto propõe um deslocamento da noção de instrumento musical da ordem do objeto utilitário para a do indivíduo, não apenas dotado de uma voz, dadas as suas características físico-acústicas, mas também de uma fala, de uma potência discursiva. Para isso convoca o pensamento do filósofo francês Gilbert Simondon que, já a partir da década de 50, trouxe uma nova perspectiva para a questão da individuação de entes não orgânicos, técnicos, tecnológicos, propondo uma ontologia do objeto técnico com sua tese Du modes de existence des Objets Techniques. O campo de experimentação para essas reflexões é um trecho do documentário Nelson Freire, onde são investigados os modos de relação entre um piano de concerto e dois indivíduos humanos com quem interage.

PALAVRAS-CHAVE: instrumento musical, experimentação, meios tecnológicos, individuação, Gilbert Simondon

ABSTRACT: This text proposes, a displacement to the concept of musical instrument, from it's acception of utilitary object to the status of an individual, defined not just by a voice, due to it's acoustical properties, but also by a speech, a discursive potential. On that behalf, the text evokes the ideas of the French philosopher Gilbert Simondon who, since the late 50's, brought to discussion a new perspective to the issue of individuation of non organic, technical beings, proposing an onthology of the technical object with his thesis The Modes of Existence of the Technical Objects. The experimental field for those reflections is a scene from the documentary film Nelson Freire, where the interactions between a Steinway piano and two human individuals are investigated.

KEYWORDS: musical instrument, experimental, technical object, individuation, Gilbert Simondon

\footnotetext{
*Tato Taborda é compositor artista sonoro dedicado à experimentação musical e professor da Universidade Federal Fluminense-UFF dedica-se também à criação de instrumentos musicais não convencionais. Pesquisa as relações da sonoridade com a dança e a cena contemporânea. Compôs em 2010 a ópera multimídia A Queda do Céu, por encomenda da Bienal de Munique.
} 
O caminho para resolver o conflito entre valores humanos e necessidades tecnológicas é quebrar as barreiras do pensamento dualístico que nos impedem de entender que tecnologia não é exploração da natureza mas fusão da natureza e do espírito humano em um novo tipo de criatura que transcende ambos.

Robert M. Pirsig: Zen and the Art of Motorcycle Maintenance.

\section{Epí(fono/filme)grafe}

O documentário do cineasta João Moreira Salles sobre o pianista Nelson Freire', traz um trecho revelador da potência discursiva de instrumentos musicais e do complexo feixe de energia e afetos que se estabelece entre esses entes e os indivíduos com quem interagem. No caso do filme, trata-se de um piano Steinway de concerto, recém saído da oficina de manutenção. $\mathrm{Na}$ cena anterior, vísceras à mostra, vemo-lo desmontado e despido de qualquer garbo. Sua máquina (o conjunto de teclas, martelos e acionamentos internos), tal qual um órgão destacado do corpo durante uma cirurgia de grande envergadura, repousa inerte e vulnerável em uma mesa, como um paciente em anestesia profunda. Com uma chave de fenda fina e comprida o técnico-cirurgião faz pequenas intervenções e ajustes aqui e ali, em busca da restauração de uma sanidade que os ouvidos e mãos do pianista, num primeiro ensaio em cena não incluída no corte final, julgaram abalada. Corte.

$\mathrm{Na}$ cena seguinte vemos o mesmo instrumento recomposto e postado no centro do palco vazio da enorme Sala São Paulo, também vazia, algumas horas antes do concerto. Nelson Freire entra, senta-se e toca o final da parte solo de um concerto para piano e orquestra, acompanhado por uma orquestra imaginária regida por um regente invisível. Ao final, após uma longa pausa ainda sentado diante do instrumento, Nelson se levanta com expressão desconsolada e diz a um interlocutor que se aproxima: - "é, não adiantou, pianos são pessoas. Sabe antipatia mútua? Pois é, eu e esse piano não nos damos bem. Na verdade nunca nos demos. Ele simplesmente não gosta de mim! Não sei por quê, nunca fiz nada para ele..."

\section{Avesso de errata (ou onde se lê isso, leia-se isso mesmo)}

A ideia inicial para esse texto era de, partindo de uma investigação do modo de existência do piano Steinway do filme Nelson Freire, ampliar essa reflexão ontológica para dois 
instrumentos-entes com os quais tenho realizado parcerias criativas nos últimos 20 anos: Geralda a mulher-orquestra ${ }^{2}$ e Felisberto o radiopiano 3 . Entretanto, essa reflexão mais ampla, que incluiría também outros instrumentos-indivíduos, como o Andarilho de Walter Smetak, ${ }^{4}$ ficou apenas no desejo do autor. Da mesma forma que os objetos técnicos um texto também pode ser pensado como um ente, com seu próprio modo de existência e desígnios. Preferiu, então, o texto-indivíduo aprofundar-se na exploração de um caso particular, protagonizado por um instrumento de caráter icônico, em busca de fundamentos para, talvez em um momento posterior, aplicá-los a um campo expandido dos instrumentos de música.

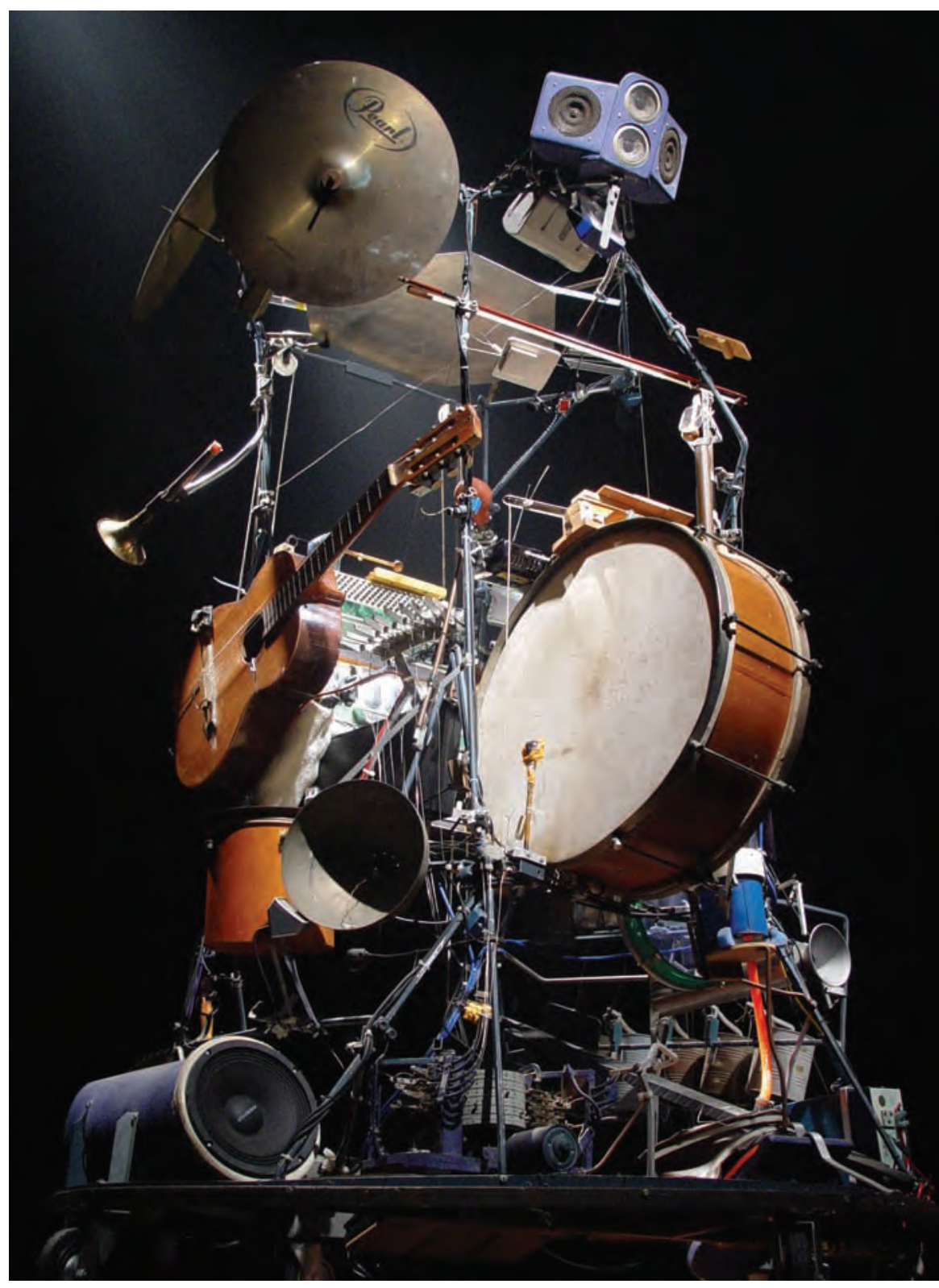

Geralda 




\section{O instrumento enquanto coisa (ou menos que)}

A idéia de instrumento de música está convencionalmente associada a um objeto imprensado entre dois sujeitos. Aquilo que Bernard Sève denomina como a "velha noção de instrumento de música," 5 define um objeto dotado de atributo se funções que o caracterizam, em primeiro lugar, como uma coisa, um "algo" com que se produzem sonoridades. Sua vocação é a de servir de meio, duto de passagem, superfície de trânsito inerte, anônima e sem significação entre duas instâncias de subjetividade reconhecida: as estruturas de pensamento de um sujeito e os ouvidos de outro. Um meio super condutivo pelo qual idéias musicais possam fluir de um sujeito que toca na direção de um sujeito que ouve (sendo que ambos podem se aglutinar no mesmo indivíduo). Nesse sentido, a significação de instrumento de músicas e irradia por um campo partilhado por termos como ferramenta, utensílio, dispositivo, artefato, aparato ou apetrecho. Se levado um pouco adiante, fora dos perímetros porosos e imprecisos do que é considerado música, o termo instrumento pode também significar modo, recurso, mecanismo, via, veículo, expediente ou mesmo documento jurídico (como uma procuração).

Em todos esses casos instrumento designa sempre um objeto, um "algo portador," por cujo corpo transitam conteúdos originados em uma instância de concepção/emissão e destinados à outra, de recepção/interpretação. Por isso, para dar conta desse trânsito da forma menos obstrutiva possível, é imperativo que se negue ao instrumento qualquer estatuto de subjetividade. Afinal se, por definição, o instrumento-via serve de ligação entre dois sujeitos, qualquer emergência subjetiva sua teria um efeito subtrativo ou aditivo no fluxo de informação despejado de uma ponta à outra. Nesse caso, o instrumento deixaria de ser portador fiel da mensagem para imprimir nela uma assinatura, como seu co-autor. No entanto, como se trata de objeto assujeitado, o instrumento pensado como meio não pode, apesar do que formulou MacLuhan a mais de meio século, ser ele próprio o meio e a mensagem. ${ }^{6}$

Consequentemente, um instrumento de música deveria, por fidelidade ao campo de significado que irradia de sua etimologia, reduzir ao mínimo qualquer impedância entre essas duas instâncias de subjetividade autorizada, a do indivíduo que pensa a música e a de quem a escuta. Portanto, por motivo da mais estrita coerência lógica, não pode em relação à elas o instrumento-duto desempenhar mais do que uma função vascular para os fluidos que por ele escorrem. No entanto, apesar de tantas restrições impostas pelo léxico que define seu 
estatuto, o instrumento-tubulação de passagem para substâncias secretadas fora de seu corpo, não deixa (pois não lhe pode evitar) de modular essas substâncias com suas qualidades intrínsecas. A matéria de que é feita seu corpo, suas dimensões, proporções e os diferentes modos com que é ativado pelo sujeito-emissor-das-substâncias imprimem nas películas que vibram nos ouvidos do sujeito-alvo-das-substâncias uma identidade, uma cor. Assim, diante da inevitável foot print acústicade sua diferença, expressa na manifestação identitária de sua natureza espectral, permite-se ao instrumento-coisa (por que não se lhe pode evitar) uma voz mas, jamais, a fala.

Enquanto isso, como diz Nietsche, repousa esse sujeito-senhor a despeito da sua ignorância, sobre um fundo impiedoso, ávido, insaciável e mortífero, agarrado a seus sonhos assim como ao dorso de um tigre. ${ }^{7}$

\section{O instrumento-indivíduo: Simondon e os modos de existência do objeto técnico}

Para um primeiro deslocamento do instrumento de música da ordem do objeto entre sujeitos para a do indivíduo que interage com outros indivíduos, convoco o pensamento do filósofo francês Gilbert Simondon que, já a partir da década de 50, trouxe uma nova perspectiva para a questão da individuação de entes não orgânicos, técnicos, tecnológicos, contribuíndo de forma pioneira para o desenvolvimento de uma verdadeira ontologia para esses indivíduos com sua tese Du modes de existence des Objets Techniques. ${ }^{8}$ Refletindo sobre a interação entre seres vivos e objetos técnicos, Simondon observou que a cultura humana desenvolveu "um sistema de defesa contra a técnica, em nome de uma defesa do homem, supondo que os objetos técnicos não contém a realidade humana." ${ }^{9}$ Essa prevenção, persistência de uma xenophobia primitiva contra um outro-diferente disfarçada por um "humanismo fácil",10 ignora que "a presença do homem nas máquinas é uma invenção perpétua. O que reside nas máquinas é o gesto humano fixado e depositado em estruturas que funcionam."111 A ignorância do sentido e dos modos de existência dos objetos técnicos opera para Simondon uma dupla alienação: do objeto e daquele que o maneja. Como antídoto, propõe que se espalhe pelo domínio dos objetos técnicos um sopro "humanista", um humanismo menos fácil, com um efeito libertador "análogo aquele desempenhado pela abolição da escravidão na afirmação do valor da pessoa humana!"?2 
Essa analogia dá a medida da inconformidade de Simondon com as barreiras erguidas entre os domínios da cultura humana e da técnica por uma perspectiva ontológica assumidamente antropocêntrica e um sentimento em relação ao objeto técnico que oscila entre a indiferença e o temor. Indiferença diante de sua não-significância de objeto útil e servil e temor diante da ameaça de que a afirmação de sua existência e identidade ponha em risco nossa posição de domínio da natureza. ${ }^{13}$ Ao mesmo tempo, denuncia uma visão autocrática da técnica (tecnocrática, portanto), para a qual "a máquina é apenas um meio: o fim é a conquista da natureza, a domesticação das forças naturais através de uma premissa de servidão. A máquina é um escravo que serve para fazer escravos."14

O reconhecimento de modos de existência particulares de indivíduos de diferentes ordens torna possível a tessitura entre eles de uma rede de relações de natureza horizontal e não-hierarquizada. Promover a interconexão entre esses indivíduos, sejam humanos ou técnicos, dissolve as barreiras erguidas pela cultura humana contra os objetos técnicos e favorece o trânsito fluido da informação de parte a parte. Para Simondon a individuação se dá, portanto, ao nível da informação, não mais da forma.

Poderia-se dizer que a forma, concebida como regularidade absoluta, tanto espacial quanto temporal, não é informação mas condição de informação. Mas a informação não é a forma, nem um conjunto de formas, ela é a variabilidade das formas, o aporte de uma variação em relação à uma forma. ${ }^{15}$

Assim, não é a forma externa do piano Steinway que ontologicamente o faz diferente do indivíduo Nelson Freire, mas a informação que o constitui e que, permanentemente atualizada, chega aos dedos e ouvidos do pianista. O Steinway, ao contrário de ser o duto, o veículo dessa informação, é a própria informação corporificada, plasmada não apenas na matéria de que é feito, madeira, marfim, ferro, aço, cortiça e feltro, mas na série convergente de instâncias de invenção que vem se sucedendo desde sua gênese histórica ${ }^{16}$ (primórdios do século XVIII com o fortepiano de Cristofori) até a sua forma atual. O indivíduo humano pode, então, na ontologia de Simondon, deslocar-se da posição de senhor-das-substâncias para a de inventor e agente capaz de fazer a "conversão em informação das formas depositadas nas máquinas ", 17 um tradutor juramentado que facilita o diálogo entre objetos técnicos de diferentes linhagens 
e deles com outros humanos. Um ouvinte atento capaz de perceber, também, variações de funcionamento como portadoras de informação.

O ruído de um motor não é, em si, valor de informação. Ele adquire esse valor pela sua variação de ritmo, de frequência ou de timbre, a alteração dos seus transientes que traduzem uma modificação de funcionamento em relação ao funcionamento que resultou da invenção. ${ }^{18}$

É a partir das informações contidas em sutis e misteriosas "modificações de funcionamento" do indivíduo-Steinway da Sala São Paulo, percebidas apenas por Nelson, que a dramaturgia do trecho do filme se desdobra. A cena nos apresenta três indivíduos, de onde irradiam três diferentes perspectivas internas à cena, sem levar em conta as milhares de outras, externas, se considerados seus espectadores. A perspectiva do técnico-cirurgião George Boyd, que faz o reparo no instrumento a pedido de Nelson é, como define Simondon, a do tecnólogo que se especializa em entender o idioma das máquinas, no caso, de uma máquina em especial, a máquina-piano. Sua atuação não é meramente técnica, funcional, mas de atualizador da série de invenções que se sucederam até a forma presente do instrumento. Se formos traçar sua genealogia, sua linhagem como diz Simondon, chegaríamos em Bartolomeo Cristofori, criador do Fortepiano, antepassado setecentista do piano moderno. Boyd, um reconhecido especialista americano-brasileiro treinado na fábrica Steinway em Nova lorque, poderia ser uma espécie de "psicólogo e sociólogo das máquinas, vivendo em meio a essa sociedade de seres técnicos dos quais é a consciência responsável e inventiva." ${ }^{19}$ No entanto, a partir da reação de Nelson quando reencontra o instrumento após a "intervenção" de Boyd, algo parece ter escapado à capacidade do especialista,como sociólogo, de mediar conflitos entre partes. Nelson parece convicto quando afirma que o indivíduo-Steinway - simplesmente não gosta de mim! Algumas hipóteses: talvez a ação desse atualizador da invenção devesse ir além de uma especializada"consciência da natureza das máquinas","20 para outra mais abrangente,uma "consciência das relações mútuas entre as máquinas e de suas relações com o homem e com os valores implicados nessas relações."21 Outra hipótese seria de que aquilo que o indivíduo-Steinway fala para Nelson, fala apenas para Nelson, não para Boyd. Afinal, Nelson propõe ao Steinway um diálogo muitíssimo mais complexo e demandoso do que aquele entabulado entre Steinway e Boyd. Um pouco como as relações de um treinador e de um jóquey com um mesmo cavalo. A resposta do cavalo às demandas do jockey durante o calor de um páreo (e a troca de informações entre os dois indivíduos) seria de outra natureza e intensidade àquelas 
obtidas pelo treinador durante a preparação. Trata-se do mesmo cavalo, enquanto forma externa e corpo orgânico, mas submetido a dois regimes de diálogo diferentes, que por sua vez revelam dois diferentes regimes de informação. Mas, afinal, que informações são essas? 0 quê, exatamente, Steinway diz a Nelson que não diz a Boyd?

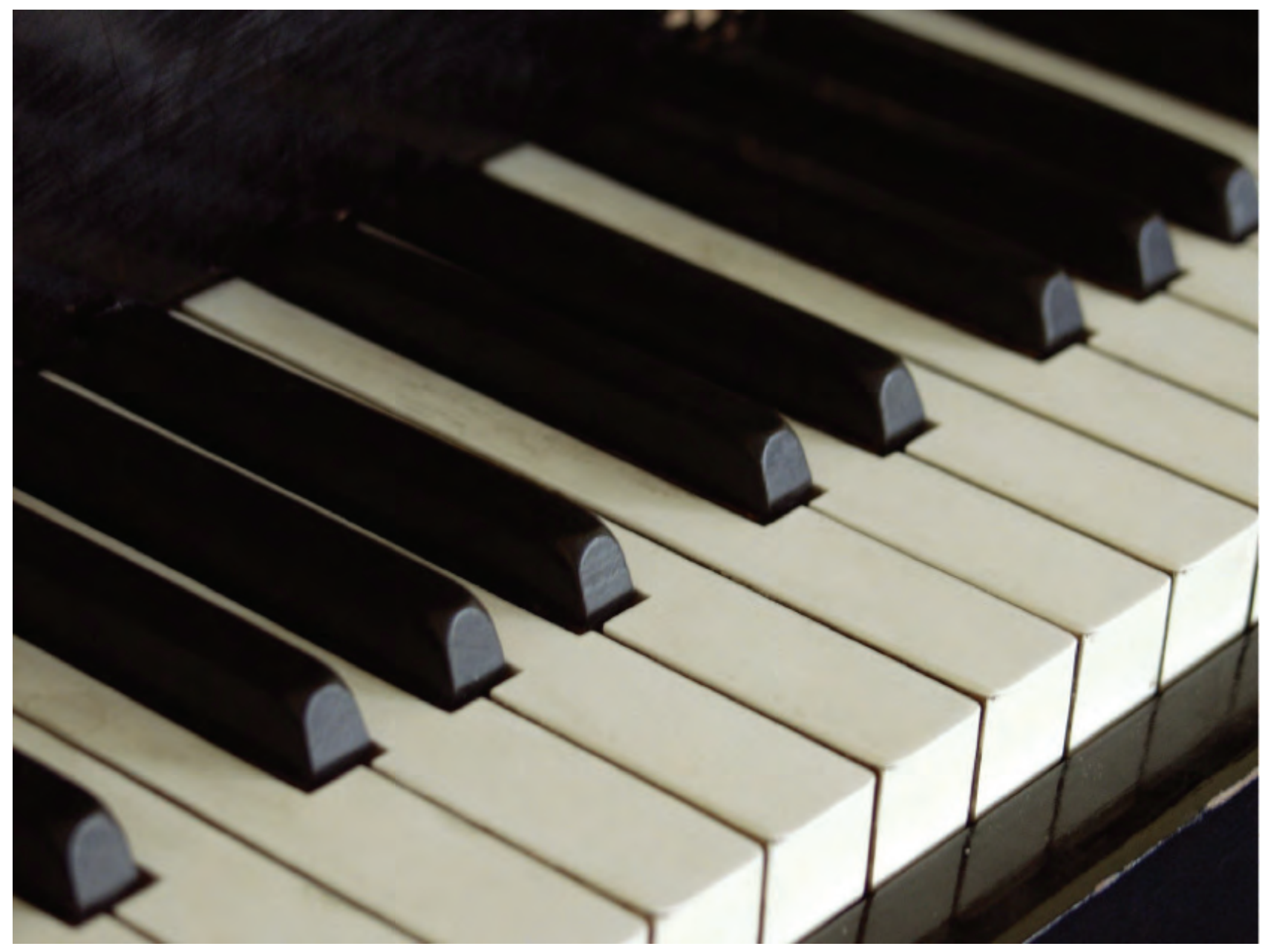


Para responder a essas perguntas precisamos voltar às reflexões sobre os modos de relação entre indivíduos técnicos e humanos e a forma com que físicamente interagem, pois essa é, precisamente, a chave para entendermos como as informações de indivíduos de diferentes ordens transitam e são mutuamente recebidas. O pensamento de Simondon evoca um sentido de continuidade entre os campos da técnica e da estética, campo ampliado que nomeia de"tecno-estético".22 Em carta ao filósofo Jacques Derrida, reflete lindamente sobre a dimensão háptica que se instaura quando humanos entram em relação íntima com ferramentas e instrumentos:

A contemplação não é uma categoria técnico-estética primária. É no uso, na ação que se torna uma experiência de certa forma orgásmica, um meio tátil e motor de estimulação. Quando uma porca que está emperrada é solta, experimenta-se uma sensação motora de prazer, uma certa alegria instrumentalizada, uma comunicação, mediada pela ferramenta, com a coisa na qual a ferramenta está trabalhando (...). É um tipo de intuição que é perceptiva-motora e sensorial. 0 corpo do operador dá e recebe. Poderíamos continuar assim quase indefinidamente, movendo-nos mais ou menos continuamente para a sensação que instrumentos artísticos dão aqueles que os tocam: o toque nas teclas do piano, sentindo a vibração e tensão das cordas da harpa ou a sensação do atritar das cordas de uma viela de roda pelo cilindro coberto de resina - é um registro quase inesgotável. Arte não é apenas objeto de contemplação; para aqueles que a praticam, é uma forma de ação que é um pouco como a prática de esportes. Pintores sentem a sensação grudenta da tinta que misturam na paleta ou espalham pela tela. A tinta pode ser mais ou menos oleosa e essa sensibilidade táctil, vibratória, entra em jogo na ação do artista, especialmente quando o pincel ou a faca entram em contato com a tela que é elasticae vai sendo tensionada contra a moldura. (...) A mesma coisa com a música: pode-se pensar, por exemplo, no peso dos abafadores do piano e na energia cinética do tocar que ordena um deslocamento dos abafadores apertando o pedal "piano",23 quando os feltros são levantados, deixam as cordas livres o que permite misturar sons em uma vibração que tende a decrescer, e esses sons sãoativados por martelos. Estética não é, afinal, a sensação "do consumidor" da obra de arte. É também, e mais originalmente, o conjunto de sensações, mais ou menos rica, dos próprios artistas: é sobre um certo contato com a material que está sendo transformado através da obra. Experimenta-se algo estético quando se faz uma solda ou aperta-se um parafuso longo. Há um espectro contínuo que conecta a estética à técnica. ${ }^{24}$

Assim, no momento em que os dedos de Nelson tocam Steinway as teclas de Steinway também lhe tocam os dedos, devolvendo-lhe o toque. O teclado de Steinway, que não é corpo 
passivo e neutro, responde com um determinado peso, uma resistência, uma impedância ao toque de Nelson. "O corpo do operador dá e recebe." ${ }^{25}$ Essa conexão entre os dois indivíduos abre um circuito para a passagem de informação como faz um interruptor de luz, quando dá passagem à carga elétrica interrompida. As teclas de Steinway afundam sob a pressão dos dedos de Nelson, que superam em pressões variadas a impedância das teclas do Steinway. Cada toque dos dedos do pianista dispara encadeamentos complexos de 28 instâncias de amortecimento e propulsão do impulso inicialno interior da máquina-piano, até que a tecla volte à posição de prontidão inicial, não sem antes golpear as cordas com o feltro denso mas elástico dos seus martelos. Essa multiplicidade de instâncias na propagação da informação pelo corpo da máquina, e num percurso de molas, pinos de pivotagem, engates, tiras de camurça, alavancas e contrapesos, introduz no sistema um teor de indeterminação considerável, considerada a perspectiva do humano que a toca. Essa indeterminação, que torna o jogo dos dois mais complexos, rasga os limites do horizonte de previsibilidade do pianista e aumenta como consequência, a possibilidade de que a resposta do piano seja recebida como informação, como surpresa fortuita ou inquietante que vem de um outro.

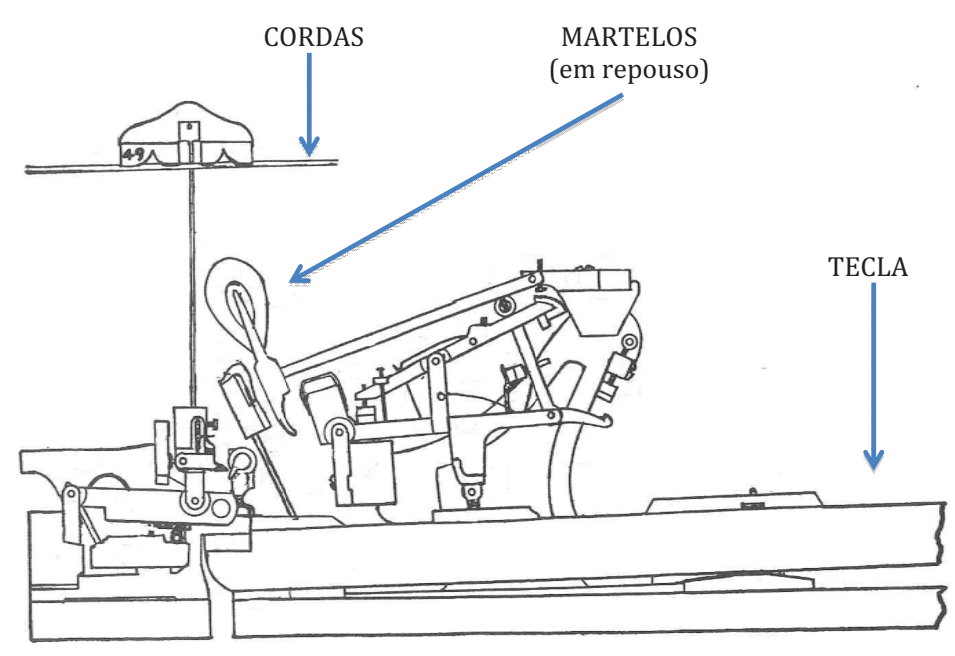

Máquina interna de um piano de concerto (28 instâncias de conversão do movimento entre o apertar da tecla e a percussão do martelo nas cordas). 
Se desenrolarmos para os dois lados, como um novelo, esse instante em que as peles dos dois indivíduos se tocam, encontraremos em uma ponta, as estruturas do pensamento de Nelson que informam seus dedos e, na outra, a sonoridade do Steinway que informa ao ar e aos ouvidos. Assim, ao mesmo tempo em que sua voz intrínseca (não uma voz genérica de piano, mas a voz desse piano) é modulada pela ação de Nelson, essa voz também informa e modula com sua concretude físico-acústica as estruturas de pensamento do pianista. Em uma ponta, música em estado potencial. Na outra, potência despejada no ar. Essas duas pontas, no entanto, se tocam, torcidas em uma banda de moebius que conecta, em fluxo contínuo, o interno ao externo. Estruturas do pensamento e sonoridades não são, portanto, limites nas extremidades de uma linha reta mas posições antípodas no movimento orbital, cíclico e retroalimentativo, da informação liberada pelos dois indivíduos.

Nesse sentido, quando Nelson diz "- o piano não gosta de mim", está se referindo à informações específicas que recebe do Steinway sob a dupla forma de pressão variável, na ponta de seus dedos e na película de seu tímpano, que indicam um desencontro entre as estruturas do pensamento que movem seus dedos, sua idéia de música, e a resposta do instrumento que recebe por via tátil/auditiva. Quanto ao terceiro personagem da cena, o tecnólogo, o que Steinway diz a Nelson diz só a Nelson, não a Boyd. Apesar de sua experiência como inventor, sociólogo e psicólogo de objetos técnicos, Boyd não tem meios ou sensores suficientes para traduzir a fala e acessar os significados que só Nelson recebe e que lhe confirmam que o Steinway está realmente indisposto consigo. O que exatamente ele fala talvez não saibamos nunca mas, felizmente, isso não é tão importante quanto reconhecermos que, de direito e de fato, o instrumento-indivíduo fala.

\section{Notas}

1 Nelson Freire é um documentário cinematográfico dirigido por João Moreira Salles sobre o pianista brasileiro. Produção Bretz Filmes, 2002.

\footnotetext{
2 Geralda é uma estrutura multi-instrumental, uma orquestra-de-um-homem-só, construída pelo compositor Tato Taborda em parcería com Alexandre Boratto, a partir de uma bolsa da Fundação Vitae, em 1993. O multi-instrumento foi construído para servir de acompanhamento à obra Canções de Musgo e Pó, escrita pelo compositor sobre poemas do poeta Matogrossense Manoel de Barros. Desde então, como um ser vivo, Geralda tem evoluído a partir das necessidades dos diferentes projetos em que tem sido utilizada. Instrumentos são acrescentados, retirados, amplificados, processados, desconstruídos, fragmentados, em um processo dinâmico em um território experimental que pode ser descrito como "tecnologia sem ponta". Apesar do multi-instrumento já existir a 10 anos,
} 
só foi "batizada" Geralda em 2002, por uma amiga que descobriu que não apenas aquela orquestra era uma entidade feminina, como estava grávida. Em seu estágio atual, Geralda conta com aproximadamente 70 fontes sonoras diferentes, entre acústicas, eletro-acústicas e eletrônicas, divididas entre sopros, cordas e percussões, formais e informais, além de dispositivos automáticos e auto-executantes. A partir de 2005 a parceria foi enriquecida com o convite ao compositor Alexandre Fenerich, que armazenou em computador as principais sonoridades de Geralda criando um novo instrumento, uma Geralda virtual, que dialoga com a sua contrapartida real. A combinação desses dois ambientes conforma um terceiro instrumento, um superinstrumento chamado Geraldona

3 Felisberto é um piano de armário sem as tampas de madeira, preparado com parafusos, garfos e diversos rádios de pilha, que são acionados pelas teclas. Isso faz de Felisberto um piano que não apenas emite, como os outros pianos, mas que também capta: um piano-antena ou um radiopiano. A gênese do instrumento foi o espetáculo Caprichosa Voz que vem do Pensamento, criado em parceria com a bailarina Maria Alice Poppe e o diretor teatral Aderbal Freire Filho inspirado na obra do escritor uruguaio Felisberto Hernandez. O escritor, que foi pianista concertista antes de se dedicar exclusivamente à literatura, tinha como característica principal em sua obra animar o inanimado. A colaboração com Felisberto também inclui a participação do compositor Alexandre Fenerich, que opera uma eletrônica em tempo real e difusão espacial realizados a partir de samples colhidas no próprio instrumento. A combinação dessas duas camadas, a do Felisberto real tocado por Tato e a sua contrapartida virtual, pilotada por Fenerich, cria uma terceira, o Felisberto Campo: um macro-instrumento, metade madeira e feltro, metade algorítimos e numeros, que integra os atributos acústicos, eletrônicos e digitais dos dois prévios em um encontro de quatro indivíduos, dois humanos e dois tecnológicos.

4 O Andarilho, nas palavras de seu inventor, "trata-se de um instrumento mendigo. Ele vive andando pelo mundo afora, também adentro, contando musicalmente suas andanças. Daí o instrumento ter função dupla. O tubo serve para tirar do Andarilho a sequência harmônica soprada. Ao mesmo tempo, a corda esticada em cima do tubo, que está ligado à uma pequena caixa acústica (um tambor de pele), é tocada por arco.

5 Sève Bernard, 2013. Pg.163

6 A expressão "o meio é a mensagem", foi criada pelo sociólogo canadense Marshall McLuhan em sua obra Os Meios de Comunicação como Extensões do Homem (Cultrix, 2002. No original, Understanding Media: the extensions of man, MacGraw Hill, 1964). MacLuhan foi pioneiro em apontar o papel interferente dos meios de comunicação em relação às mensagens que eles, supostamente, apenas veícularíam. É notável a semelhança entre os pensamentos de MacLuhan e Simondon, guardadas as diferenças de seus campos epistemológicos, particularmente pela atenção que dedicaram às interações sociais entre indivíduos humanos e meios tecnológicos.

7 NIETZSCHE, F. 2009 (pg. 530)

8 SIMONDON, Gilbert. 1989.

9 lbd. Pg 9

10 lbd. Pg 9

11 lbd. Pg12

12 SIMONDON, G. 1989 (pg 9)

13 Vide sua corporificação nos mitos do Golem, Frankenstein, Hal, o computador autoritário e super-zeloso do 2001 de Kubrick, 0 Exterminador do Futuro ou mesmo, de forma mais assustadoramente descorporificada, no "bug do milênio"

$14 \mathrm{lbd} . \operatorname{Pg} 127$ 
15 lbd. Pg 137

16 Simondon refere-se frequentemente à noção de gênese como ontogênese, uma gênese em devir e permanente atualização. Cada objeto técnico desdobra sua gênese em uma linhagem, de ancestrais e sucessores, definida pela série de versões que se sucedem em seu processo de aperfeiçoamento. Na origem de cada uma dessas séries, encontraremos sempre um ato definido de invenção (pg 43). Esse processo é referido por Simondon como de "concretização", na medida em que as séries de versões fazem um arco que parte do abstrato na direção do concreto. Quanto mais concretos vão se tornando em seu processo de aperfeiçoamento, mais os objetos técnicos se aproximam de objetos naturais.

$17 \mathrm{lbd}$. Pg 139

$18 \mathrm{lbd}$. Pg 139

$19 \mathrm{lbd}$. Pg 13

$20 \mathrm{lbd}$. Pg.13

$21 \mathrm{lbd}$ Pg. 13

22 SIMONDON, G. 2012. pg 1

230 pedal "piano," também chamado como pedal una corda tem um efeito de surdina. Quando pressionado, desloca lateralmente o conjunto dos martelos para que, ao invés de percutirem nas 3 cordas afinadas em uníssono o façam em apenas uma, atenuando a intensidade do som.

$24 \mathrm{lbd} . \mathrm{pg} 3$

$25 \mathrm{lbd} . \mathrm{pg} 3$

\section{Referências}

NIETZSCHE, Friedrich. 'Sobre Verdade e Mentira no Sentido Extra-moral' In: Antologia de Textos Filosóficos. MARÇAL, J. (org.) Curitiba: Seed, 2009, Tradução:Torres Filho, R.

PIRSIG, Robert M.. Zen and the Arte of Motorcycle Maintenance. New York: Bantam, 1984.

SCHAEFFER, Pierre. Traité des objets musicaux. Paris: Seuil, 1966.

SCHAFER, R. Murray. The Tuning of the World. New York: Random House, 1977.

SÈVE, Bernard, L'Instrument de musique: Une étude philosophique. Paris: Seuil, 2013.

SIMONDON, Gilbert, Du mode de existence des object techniques. Paris: Aubier, 1989.

'On Techno-Aesthetics' In Parrhesia no 14, 2012, tradução Arne de Boever, (pg 1-8). 